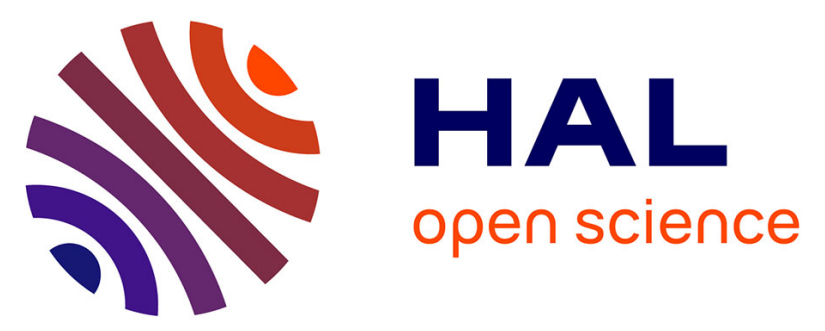

\title{
INVESTIGATION OF IN-FLIGHT PARTICLE CHARACTERISTICS AND MICROSTRUCTURAL EFFECTS ON OPTICAL PROPERTIES OF YSZ PLASMA-SPRAYED COATINGS
}

Vincent Debout, Armelle Vardelle, Pierre Abelard, Pierre Fauchais, Erick

Meillot, Eric Bruneton, Franck Enguehard, Sabine Schelz

\section{To cite this version:}

Vincent Debout, Armelle Vardelle, Pierre Abelard, Pierre Fauchais, Erick Meillot, et al.. INVESTIGATION OF IN-FLIGHT PARTICLE CHARACTERISTICS AND MICROSTRUCTURAL EFFECTS ON OPTICAL PROPERTIES OF YSZ PLASMA-SPRAYED COATINGS. High Technology Plasma Processes, May 2006, St Petersburg, Russia. 10.1615/HighTempMatProc.v11.i3.10 . hal-01287482

\author{
HAL Id: hal-01287482 \\ https://hal.science/hal-01287482
}

Submitted on 14 Mar 2016

HAL is a multi-disciplinary open access archive for the deposit and dissemination of scientific research documents, whether they are published or not. The documents may come from teaching and research institutions in France or abroad, or from public or private research centers.
L'archive ouverte pluridisciplinaire HAL, est destinée au dépôt et à la diffusion de documents scientifiques de niveau recherche, publiés ou non, émanant des établissements d'enseignement et de recherche français ou étrangers, des laboratoires publics ou privés. 


\title{
INVESTIGATION OF IN-FLIGHT PARTICLE CHARACTERISTICS AND MICROSTRUCTURAL EFFECTS ON OPTICAL PROPERTIES OF YSZ PLASMA-SPRAYED COATINGS
}

\author{
V. Debout * A. Vardelle, P. Abélard, P. Fauchais \\ CNRS - SPCTS, University of Limoges, Limoges, France \\ E. Meillot, E. Bruneton, F. Enguehard, S. Schelz \\ CEA Le Ripault, Monts, France
}

\begin{abstract}
The purpose of this study is to investigate the microstructural effects of yttria-stabilized zirconia (YSZ) plasma-sprayed coatings on their optical properties in order to improve the thermal performance of these coatings that are often used as thermal barrier coatings (TBCs). Four coatings with significant microstructural differences have been manufactured. A preliminary investigation of in-flight particle characteristics has been performed to select the spray conditions. This investigation used two complementary particle diagnostic tools: the DPV2000 system and a particle collection device. Both hemispherical transmittance and reflectance spectra of the coatings have been investigated over the $0.25-10 \mu \mathrm{m}$ wavelength range. The Gouesbet-Maheu four-flux model has been implemented to calculate the absorption and scattering coefficients. Their variations are discussed in terms of microstructural effects.
\end{abstract}

Keywords: Plasma spraying; In-flight particle diagnostics; Transmittance; Scattering and absorption coefficients.

\section{Introduction}

Atmospheric plasma spraying (APS) is widely used to produce ceramic thermal barrier coatings (TBCs). A TBC is a dual-layered system: the top ceramic layer, commonly yttriastabilized or partially stabilized zirconia (YSZ), provides thermal insulation to engine components while the bond coat (NiCrAlY) increases the oxidation resistance and adapts the difference in expansion coefficient between the top coat and the substrate. Understanding the link between the processing parameters, resulting microstructural features and macroscopic properties is the key to ensure better TBC performances. Accordingly, the radiative properties of YSZ plasma-sprayed coatings must be investigated since the radiative transfer is the major

\footnotetext{
* Corresponding author. Tel : +332473446 82; fax: +33247345108

E-mail address: debout@ensil.unilim.fr
} 
heat transfer process at service temperatures [1]. This work is intended to establish relationships between the microstructural features of YSZ plasma-sprayed coatings and their radiative properties.

The first section describes the experimental procedure. It includes: (1) the particle in-flight monitoring with the DPV2000 system and a particle collection device to engineer coatings with microstructural differences; (2) a thorough characterization of the resulting coatings to provide a global description of the microstructural features; (3) the reflectance and transmittance measurements over the $0.25-10 \mu \mathrm{m}$ wavelength range on annealed samples in oxidizing atmosphere at $500^{\circ} \mathrm{C}$ for $24 \mathrm{~h}$. The second section presents the experimental results and discusses the microstructure in relation to the in-flight diagnostic results. Finally, the last section analyses the potential of the four-flux model to investigate the correlations between microstructure and radiative properties.

\section{Experimental procedure}

Materials and plasma spraying equipment

The sprayed powder is a commercial 7\%-wt $\mathrm{Y}_{2} \mathrm{O}_{3}$ partially-stabilized $\mathrm{ZrO}_{2}$ powder (Amperit 827.054 from H.C Stark) with a $10-45 \mu \mathrm{m}$ particle size distribution. The feedstock manufacturing process is spray drying, agglomeration and sintering. It results in globular and porous particles as shown in Fig. 1.
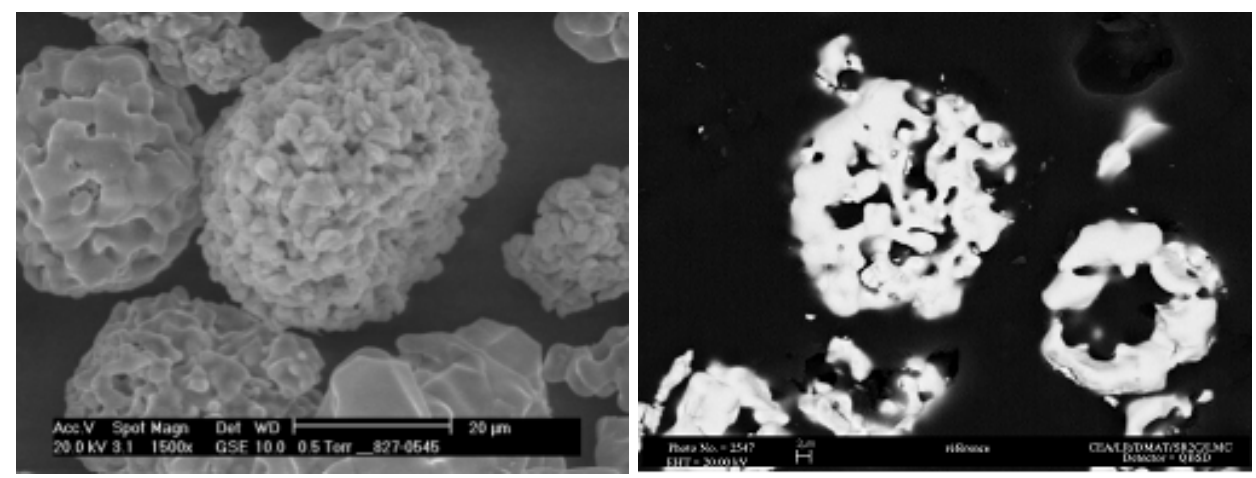

Figure 1: Morphology and cross section of $\mathrm{ZrO}_{2}-7 w t . \% \mathrm{Y}_{2} \mathrm{O}_{3}$ particles

A X13M stainless steel grade (Aubert\&Duval, France) has been selected as substrate material in order to minimize the expansion mismatch stress during the coating formation as its expansion coefficient $\alpha$ is very close to that of YSZ: at $25^{\circ} \mathrm{C}, \alpha \times 13 \mathrm{M}=10.6 \times 10^{-6}{ }^{\circ} \mathrm{C}^{-1}$ and $\alpha$ $\mathrm{YsZ}=10.5 \times 10^{-6}{ }^{\circ} \mathrm{C}^{-1}$. The disk-shape substrates $(25 \mathrm{~mm}$ in diameter and $5 \mathrm{~mm}$ in thickness $)$ have been grit-blasted to $\mathrm{Ra}=4 \mu \mathrm{m}$ and disposed on a cylindrical holder ( $160 \mathrm{~mm}$ in diameter) at a stand-off distance of $120 \mathrm{~mm}$ from the spray gun nozzle exit. 
Plasma-sprayed $500 \mu \mathrm{m}$-thick coatings have been manufactured with a F4-VB torch (Sulzer Metco AG, Switzeland). The powder has been injected through a 1.5-mm internal diameter injector perpendicular to the plasma torch axis and located at $6 \mathrm{~mm}$ from the nozzle exit. The powder carrier gas has been adjusted in such a way that the median trajectory of the spray jet made an angle of $3.5^{\circ}$ with the torch axis. During spraying, the substrate and coating surface temperature, monitored continously with an Ircon pyrometer $(8<\lambda<14 \mu \mathrm{m}, 10 \mathrm{~Hz})$, has been adjusted at $200^{\circ} \mathrm{C}$ (transition temperature) by an argon cryogenic cooling system. Below this temperature value, the impacting droplets splatter into several interconnected fragments while above, the droplets retain their coherence and spread out in the form of disks [2]. In addition, this temperature makes it possible to restrict the substrate oxidation during the preheating stage.

To engineer coatings with significant microstructural differences, the following operating parameters have been varied: torch nozzle internal diameter (6 or $8 \mathrm{~mm}$ ), arc current (320 to $600 \mathrm{~A}$ ), gas mixture composition (binary or ternary mixtures of argon, hydrogen and helium) and gas flow rates. The spray conditions have been selected by using particle diagnostic tools to obtain a large range of in-flight particle characteristics.

\section{$\underline{\text { Particle diagnostic tools }}$}

Particle in-flight diagnostics have been performed, at the stand-off distance $(120 \mathrm{~mm})$ without the substrate, using a DPV2000 system and a device to collect the in-flight particles.

The Tecnar DPV2000 system provides temperature and velocity distributions by collecting the thermal radiation emitted by hot particles with an optical sensing head. The temperature is determined by using a two-color fast pyrometer working at $\lambda_{1}=792 \mu \mathrm{m}$ and $\lambda_{2}=1004 \mu \mathrm{m}$ and assuming that the material behaves as a grey body [3]. However, at these two wavelength values, YSZ is reported to be translucent at high temperature [1] and thermal gradients could exist within particles. Besides, the DPV2000 system records signal issued from hot particles emitted fluxes that means that overheated small particles and larger ones at a temperature lower by hundreds of $\mathrm{K}$ can give the same thermal radiation due to their surface ratio. Therefore, in this paper, the measured temperatures are not absolute values. However, the trends they give allows the comparison of the spray conditions.

An in-flight particle collecting system has been designed in order to study the melting state of particles when they impact on the substrate. It consists of four main parts: a stainless steel barrel $(100 \mathrm{~mm}$ in internal diameter and $200 \mathrm{~mm}$ in length) with four $12.5 \mathrm{~mm}$-sized blowholes, 
a copper water-cooled upper part with a $25 \mathrm{~mm}$-sized hole, a protective stainless steel top diaphragm and a copper bottom part with two argon cryogenic nozzles. The liquid argon tank pressure and the argon atomizing gas pressure have been adjusted according to the spray conditions in order to quench the sprayed powder. The whole has been positionned horizontally at $120 \mathrm{~mm}$ from the nozzle exit and aligned with the center of the sprayed spot.

After collection, scanning electronic microscopy (SEM) observations of particle cross sections have been performed and a digital image analysis routine has been implemented to evaluate the melting state of the collected particles. Since a good heat treatment of particles in the plasma jet usually results in denser spheroidized particles, the morphology of the particles and their internal porosity content have been studied to quantify the melting state. Two magnifications $\times 50$ and $\times 250$ have been chosen to evaluate these criteria. The morphological analysis has been performed on a $1600-\mu \mathrm{m}$ x $1200-\mu \mathrm{m}$ field of view which includes $1000-$ 2000 particles on average. This enables a proper statistical analysis. The porosity determination has been performed using a $320-\mu \mathrm{m}$ x $240-\mu \mathrm{m}$ field of view. Before analysis, the micrographs have been treated by a software to discard the particles in contact with the image edges, separate the agglomerated particles and remove the particle splinters due to the metallographic preparation.

\section{Microstructural analysis of the coatings}

The coating microstructure has been observed by using optical microscopy (OM) and scanning electronic microscopy (SEM) while the porous and crack network has been characterized by the combination of three techniques :

(1) Archimedes Porosimetry that provides the open porosity level $\mathrm{P}_{\mathrm{o}}$.

(2) Mercury Intrusion Porosimetry (MIP) that gives the open porosity level and pore size distribution. The measurable pore size ranges between $100 \mu \mathrm{m}$ and a few nanometers by applying pressure from 0.1 up to $400 \mathrm{MPa}$ (Micrometrics Autopore III 9410).

(3) Image Analysis (Clemex Vision Software) that is performed on ten successive fields of view of $3.5 \mathrm{~mm}^{2}$ with an optical microscope (Nikon Microphot Fxa). However, this technique cannot measure submicronic pores due to the resolution of the objective lens.

For volumetric methods (1) and (2) used to characterize the open porosity, free-standing samples have been prepared by removing the coatings from the stainless substrates by using acidic dissolution. 


\section{Annealing}

A previous study [4] has demonstrated that the oxygen loss in the YSZ material during the deposition process has a strong effect on the resulting optical properties. To reduce this effect, all samples have been annealed in air at $500^{\circ} \mathrm{C}$ for $24 \mathrm{~h}$ before.

\section{Optical characterization tools}

The reflectance and transmittance measurements of the plasma-sprayed free-standing coatings have been performed over the $0.25-10-\mu \mathrm{m}$ wavelength range by means of two spectrometers: a Varian Cary 5000 spectrometer for the $0.25-2.5-\mu \mathrm{m}$ wavelength range and a Mid-IR Bruker IF66v/s spectrometer for the $1.5-10-\mu \mathrm{m}$ range.

Since the plasma-sprayed coatings exhibit highly scattering features [5], integrating spheres with a reflecting inner coating have been mounted to collect the hemispherical flux. Data acquisition has been performed under soft vacuum $(<2000 \mathrm{~Pa})$ to avoid, as much as possible, the absorption bands of $\mathrm{H}_{2} \mathrm{O}$ and $\mathrm{CO}_{2}$.

The data measured with the Brucker spectrometer have been adjusted and merged with the Varian data between 1.5 to $2.5 \mu \mathrm{m}$ by using the dedicated OPUS software (Bruker Optik $\mathrm{GmbH}$ ) in order to examine the spectra over the entire wavelength range.

\section{Results and discussion}

$\underline{\text { Particle diagnostics and spray conditions }}$

The DPV2000 monitoring made it possible to select 4 sets of spray conditions among 25 sets. The selected spray conditions and corresponding particle in-flight parameters are summarized in Table 1. The reported data correspond to the mean velocity and temperature values calculated from more than 1000 individual particles recorded in the plasma jet where the maximun particle flux is detected. Therefore, the standard deviation values encompass variations due to the particle size distribution, process instabilities (powder feeding and plasma jet fluctuations) and measurement errors.

Table 1 : Spraying conditions and corresponding in-flight particle characteristics

\begin{tabular}{|c|ccccc|cc|}
\hline $\begin{array}{c}\text { Condition } \\
\text { set } \\
\text { number }\end{array}$ & $\begin{array}{c}\text { Plasma gas flow } \\
\text { rates }(\mathrm{slpm}) \\
\mathrm{Ar} / \mathrm{He} / \mathrm{H}_{2}\end{array}$ & $\begin{array}{c}\text { Total gas } \\
\text { flow rate } \\
\left(\mathrm{x} 10^{-4} \mathrm{~kg} / \mathrm{s}\right)\end{array}$ & $\begin{array}{c}\text { current } \\
(\mathrm{A})\end{array}$ & $\begin{array}{c}\text { Specific } \\
\text { enthalpy } \\
(\mathrm{MJ} / \mathrm{kg})\end{array}$ & $\begin{array}{c}\text { Nozzle } \\
\text { diameter } \\
(\mathrm{mm})\end{array}$ & \multicolumn{2}{|c|}{$\begin{array}{c}\text { Particle in-flight } \\
\text { parameters }\end{array}$} \\
\hline $\mathbf{1}$ & $45 / 0 / 15$ & 1.359 & 600 & 19.5 & 6 & $3014 \pm 185$ & $280 \pm 60$ \\
\hline $\mathbf{2}$ & $65 / 30 / 5$ & 2.027 & 550 & 10.7 & 6 & $2767 \pm 210$ & $300 \pm 70$ \\
\hline $\mathbf{3}$ & $12 / 45 / 3$ & 0.495 & 450 & 24.0 & 6 & $2730 \pm 130$ & $150 \pm 25$ \\
\hline $\mathbf{4}$ & $6 / 12 / 1.5$ & 0.226 & 450 & 14.2 & 8 & $2800 \pm 105$ & $50 \pm 10$ \\
\hline
\end{tabular}


The spray conditions $1 \& 2$ provide high particle velocity range $(280-300 \mathrm{~m} / \mathrm{s})$ due to high gas flow rate, high current intensity (550-600A) and a 6mm-diameter nozzle. Conversely, the lower particle velocity values have been achieved by decreasing both the plasma gas flow rate and the arc current intensity for the spray condition 3, and also by increasing the internal diameter nozzle $(8 \mathrm{~mm})$ for the spray condition 4.

Regarding the mean particle temperature, the selected spray conditions can be subdivided into two groups: a high temperature group (condition 1) and a "melting-point" group (conditions 2-3-4) with a temperature range close to the YSZ melting temperature $\left(2750^{\circ} \mathrm{C}\right)$. As already mentionned, these absolute values are not meaningful to quantify the melting state of particles which depends on their dwelling time in the plasma jet and plasma-particle heat transfer.

SEM cross sections of original and collected powders are shown in Fig.1 and Fig.2, respectively. It can be seen that depending on the spray conditions, the argon-quenched particles differ both in shape and internal porosity content which illustrate different melting degrees. A digital analysis method was used to perform some statistical analysis (Table 2) of the morphology and internal porosity of particles after their heat treatement in the plasma jet. The internal porosity features have been determined on the micrographs of Fig. 2 while the mean shape factor $\mathrm{SF}\left(\mathrm{SF}=4 \pi \mathrm{A} / \mathrm{P}^{2}\right.$ with $\mathrm{A}$ the particle area and $\mathrm{P}$ its perimeter) has been measured over about 1000 particles on larger field images, not reported in this paper.

Table 2 : Digital image analysis of SEM particle cross-section observations

\begin{tabular}{cccc}
\hline Powder sample number & $\begin{array}{c}\text { Shape Factor } \\
0<\mathrm{SF}<1\end{array}$ & $\begin{array}{c}\text { Relative porous } \\
\text { area per particle }(\%)\end{array}$ & $\begin{array}{c}\text { Mean size of internal pores } \\
(\mu \mathrm{m})\end{array}$ \\
\hline Original powder & $0.92 \pm 0.14$ & 7.4 & 1.54 \\
\hline $\mathbf{1}$ & $0.97 \pm 0.08$ & 2.2 & 0.60 \\
\hline $\mathbf{2}$ & $0.89 \pm 0.16$ & 7.1 & 1.08 \\
\hline $\mathbf{3}$ & $0.95 \pm 0.07$ & 3.3 & 1.18 \\
\hline $\mathbf{4}$ & $0.93 \pm 0.11$ & 1.5 & 0.78 \\
\hline
\end{tabular}

The image analysis indicates that the treatment of the particles in the plasma jet results both in an increase in the particle sphericity and a decrease in their porous area content and mean size of internal pores. The standard deviation obtained for the shape factor can be explained by the original powder size distribution which brings about different heat treatements in the plasma flow. The powder sample 1 exhibits the highest shape factor with the lowest mean size of internal porosity ; this indicates a good melting state of particles prior to their impact onto the susbtrate. It is consistent with the order of magnitude of the temperature measured by the DPV2000 system. However, it is preferable to discuss such data in terms of particle dwelling 
time and plasma thermal properties since the sets 2,3 and 4 of the spray conditions exhibit about the same mean temperatures but different melting states.
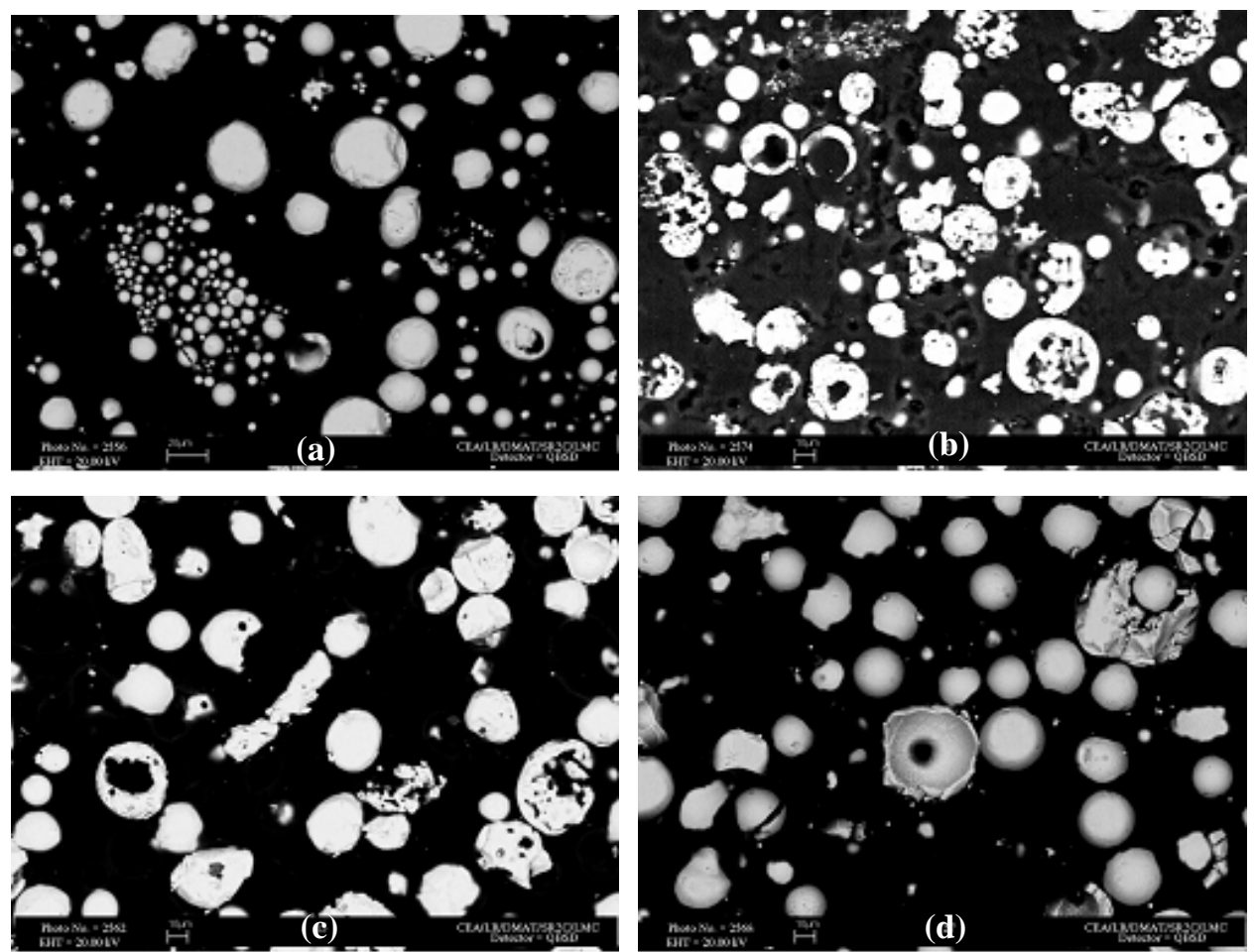

Figure 2 : SEM cross-section of collected powders (a): condition 1, (b): condition 2, (c): condition 3, (d): condition 4.

- Condition 1: The combination of high hydrogen content (25\%vol.) in the plasma-forming gas and high specific plasma enthalpy (Table 1) results in the full melting of particles. Indeed, the hydrogen increases the thermal conductivity of the plasma and thus, improves the plasma-particle heat transfer.

- Condition 2: Despite a velocity similar to that of condition 1, the collected particles are highly porous and less spherical (Table 2). These results illustrate a poor melting state of particles which can be related to the low thermal conductivity (hydrogen content: $5 \%$ vol.) and low specific enthalpy of the plasma gas.

- Condition 3: The extension of the particle residence time, due to a low plasma gas flow rate combined with a high specific enthalpy and a good thermal conductivity over $10000 \mathrm{~K}$ (high $\mathrm{He}$ content), slightly improves the plasma-particle heat transfer. The collected particles exhibit an average melting state with a good sphericity and a moderate porosity level.

- Condition 4: The variation of the internal porosity content and pore mean size is consistent with a good melting of particles promoted by the long dwelling time of the in- 
flight particles in the plasma jet (low particle velocity). Some hollow particles with a thick wall made up of melted elementary particles of the initial agglomerates can be observed. They probably correspond to large particles with temperature over, but close to, the material melting temperature. Therefore the viscosity of the molten particle is too high to permit the gas included in the particle to escape through the molten shell.

\section{$\underline{\text { Coating microstructure and porosity }}$}

SEM observations of the resulting coatings are reported in Fig. 3. Their microstructure can be interpreted with respect to the in-flight particle characteristics since these characteristics govern the viscosity and kinetic energy of the impacting particles and thus control the flattening and solidification processes [6]. Mac Pherson has shown that if the spreading process is complete before solidification, the flattening degree can be calculated using the Madjeski's formula [7]:

$$
\mathrm{D} / \mathrm{d}=1.2941 \times \mathrm{Re}^{0.2}
$$

where $\mathrm{d}$ is the average particle diameter, $\mathrm{D}$ the resulting lamella diameter, Re (Reynolds number) $=\rho . \mathrm{v} . \mathrm{d} / \mu$ with $\mathrm{v}$ the particle impact velocity, $\rho$ the density of the material $\left(6030 \mathrm{~kg} / \mathrm{m}^{3}\right)$ and $\mu$ the molten material dynamic viscosity. Due to the lack of data referring to liquid zirconia viscosity, $\mu$ has been estimated by using the equation of Shinoda [8]: $\mu$ $[\mathrm{kg} / \mathrm{m} . \mathrm{s}]=0.0037 . \exp (6100 / \mathrm{T}(\mathrm{K}))$, which has been evaluated through the measurements of YSZ flattening degree.

Table 3: Estimation of the flattening degree using the Madjeski's formula

\begin{tabular}{ccccc}
\hline Sample number & 1 & 2 & 3 & 4 \\
\hline Flattening degree D/d & 6.12 & 6.02 & 5.21 & 4.17 \\
\hline
\end{tabular}

The sets 1 and 2 of spray parameters are characterized by high particle velocity (Table 1) that bring about an important deformation of the impinging particles, a high flattening degree (Table 3) and thus, thin lamellae. This is consistent with the corresponding SEM micrographs (Fig.3a and 3b) where the lamellar structure is difficult to discern. Conversely, the spray condition 4 that leads to low particle velocity and temperature at impact, leads to a poor flattening of the particles on the substrate. The resulting coating has a marked lamellar microstructure and contains some partially-melted particles (Fig.3d). The observed coarse pores can be related to the pull-out of loosely-bonded particles in the coating during the grinding and polishing stages. 

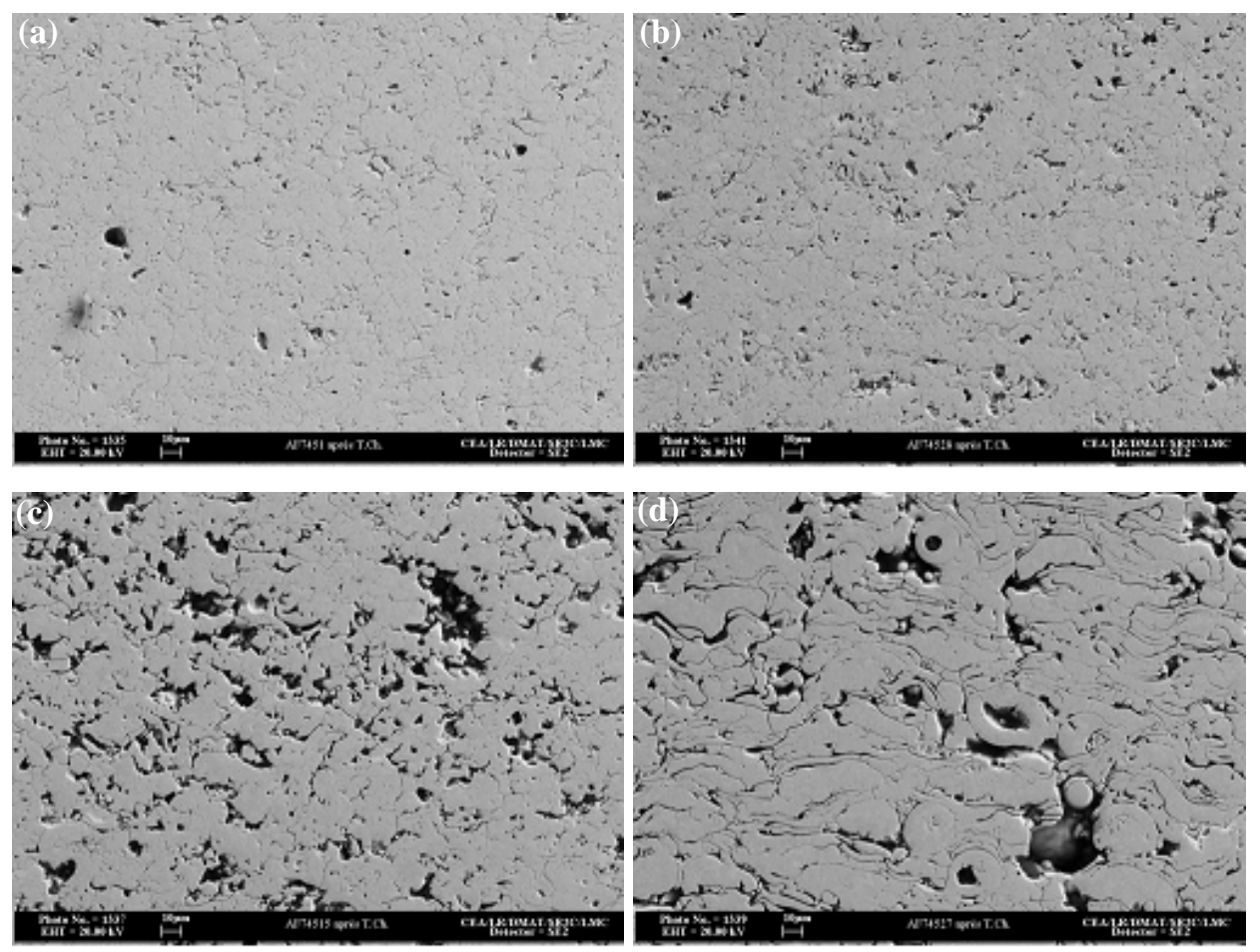

Figure 3: SEM micrographs of YSZ plasma-sprayed coatings (a): coating 1, (b): coating 2, (c): coating 3, (d): coating 4.

The results of the coating porosity estimated by the three methods described before, are given in Table 4. As image analysis failed to measure the submicron-sized pores, the overall pore content is lower except for sample 4 in which pull-outs lead to an overestimation of the porosity value. Thus, the four spray conditions not only lead to a large range of porosity (10$22 \%$ ) but also to different mean pore size as illustrated in Table 4: coatings 3 and 4 contain micron-sized pores while coatings 1 and 2 have a distribution of submicron-sized pores.

Table 4: Coating porosity features measured with different methods

\begin{tabular}{|c|ccc|c|}
\hline \multirow{2}{*}{$\begin{array}{c}\text { Sample } \\
\text { number }\end{array}$} & \multicolumn{3}{|c|}{ Porosity level } & $\begin{array}{c}\text { Pore mean diameter }(\mu \mathrm{m}) \\
\text { (determined by MIP) }\end{array}$ \\
\cline { 2 - 4 } & MIP (\%) & Image analysis (\%) & Archimedes (\%) & 0.25 \\
\hline $\mathbf{1}$ & $11 \pm 1$ & $9.9 \pm 0.4$ & $10.5 \pm 0.4$ & 0.2 \\
\hline $\mathbf{2}$ & $12 \pm 1$ & $11.8 \pm 0.9$ & $12.3 \pm 0.9$ & 1.6 \\
\hline $\mathbf{3}$ & $23 \pm 1$ & $22.4 \pm 1.8$ & $22.7 \pm 0.7$ & 1 \\
\hline $\mathbf{4}$ & $18 \pm 1$ & $22.2 \pm 2.7$ & $17.0 \pm 1.0$ & \\
\hline
\end{tabular}

\section{$\underline{\text { Optical properties }}$}

To investigate the radiative properties of the samples, a parameter inversion method has been implemented to calculate the scattering and absorption coefficients. This method involves minimizing the residual sum of squares between the computed reflectance and transmittance derived from the Gouesbet-Maheu four-flux model [9] and from the experimental spectra. 
The hemispherical transmittance $\mathrm{T}$ and reflectance $\mathrm{R}$ measurements have been performed over the $0.5-10 \mu \mathrm{m}$ wavelength range on freestanding $500 \mu \mathrm{m}$-thick coatings annealed at $500^{\circ} \mathrm{C}$ during $24 \mathrm{~h}$. The transmittance spectra are shown in Fig. 4. The drop in transmittance between 2.5 and $4 \mu \mathrm{m}$ can be related to the absorption bands of water.

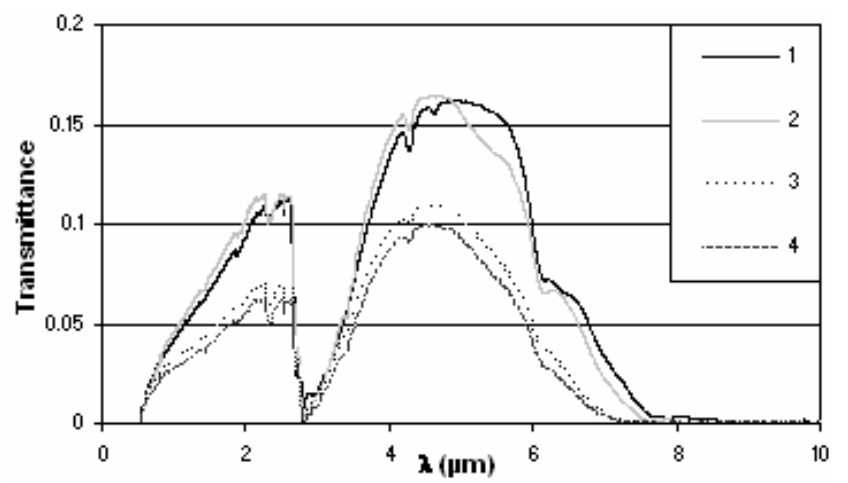

Figure 4 : Transmittance spectra of coatings annealed at $500^{\circ} \mathrm{C}$ during $24 \mathrm{~h}$

The optical behavior of the YSZ plasma-sprayed coatings can be divided into two wavelength zones according to the variation of the absorption and scattering coefficients (Fig. 5). In region $I(\lambda<5 \mu \mathrm{m})$, the plasma-sprayed coatings exhibit a highly scattering feature as reported elsewhere [5]. In region II $(5 \mu \mathrm{m}<\lambda)$, the absorption coefficient becomes high. This is consistent with the increase in the extinction index $\kappa$ of the YSZ material.
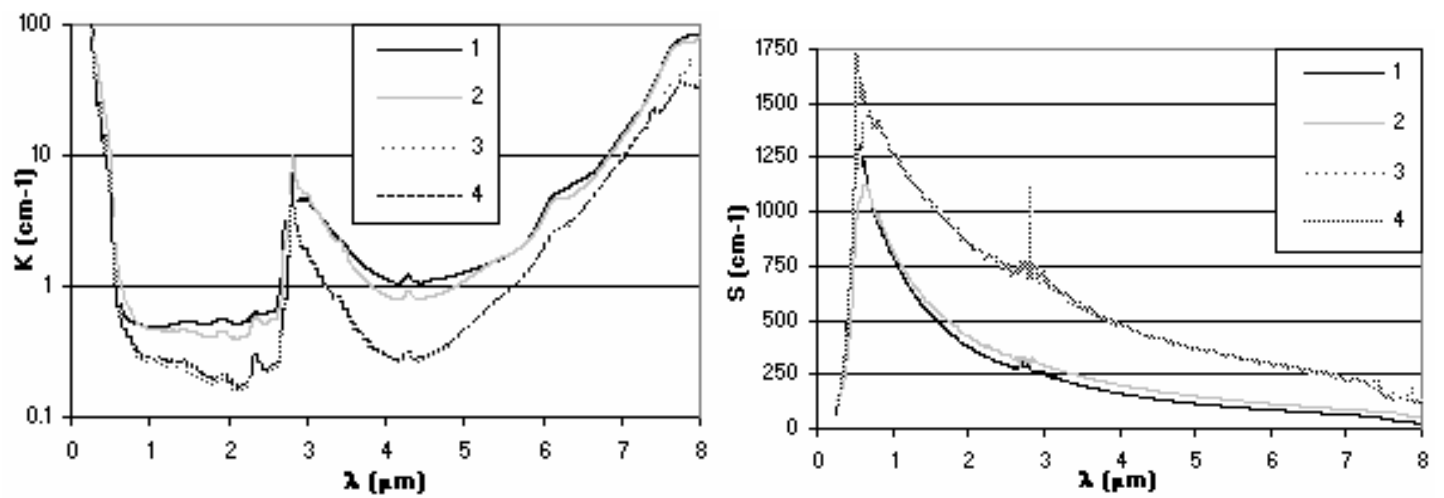

Figure 5: Absorption and scattering coefficients of the YSZ plasma-sprayed coatings

From these variations, two radiative behaviors should be emphasized:

(1) Coatings 1 and 2 exhibit low backscattering and moderate absorption features: this is consistent with their high transmittance values. By regarding the microstructure features, such a behavior can be related both to the low porosity content (10-12\%) and the submicron-sized pores (Table 3).

(2) Coatings 3 and 4 display lower transmittance spectra due to high backscattering coefficients. This can be attributed both to the high porosity content and the large-sized pores. 
These results indicate that the scattering process should be investigated in relation to the porosity features such as the distribution, the mean size and the shape of the pores. The size effect can be interpreted by introducing the pore size parameter $\mathrm{x}$ which compares the pore radius $r$ to the wavelength in the matter: $\mathrm{x}=\left(2 \pi \cdot \mathrm{r} \cdot \mathrm{n}_{\mathrm{YSZ}}\right) / \lambda$ where $\mathrm{n}_{\mathrm{YSZ}}$ is the refractive index of YSZ material. When $\mathrm{x}<1$, the scattering process decreases as $1 / \lambda^{4}$ (Rayleigh regime) and the distribution of the scattered radiation tends to be isotropic [10] as it is observed for coatings 1 and 2 beyond $1.5 \mu \mathrm{m}$. This is consistent with the lower backscattering values and thus the higher transmittance for both coatings while for the coatings 3 and 4 the mean size parameter $\mathrm{x}$ is larger than 1 all over the $0.25-8 \mu \mathrm{m}$ range.

\section{Conclusion}

In this study, four YSZ plasma-sprayed coatings have been manufactured to establish correlations between the microstructure features and the radiative properties of coatings. The spray parameters have been selected by using two complementary particle diagnostic tools: the DPV2000 system and a particle collecting set-up. The particle melting state has been investigated by studying the cross section of the collected particles. A digital analysis method was used to provide two criteria to quantify the particle melting state: the shape factor and the internal pore features (size and ratio). These results have been discussed in terms of the particle dwelling time in the plasma jet and plasma-particle heat transfer. The resulting microstructures differ in the content, size and shape of pores and thus provide a suitable case study.

The transmittance spectra of these four annealed coatings exhibit consistent differences over the $0.25-8 \mu \mathrm{m}$ wavelength range. The evaluation of absorption and scattering coefficients enables to identify the effects of some pore features such as size and content. To manage efficient thermal barriers, plasma-sprayed coatings with high porosity level and micron-sized pores should be engineered.

A comprehensive study of the radiative properties of YSZ plasma-sprayed coatings requires simplifying the present case by separating the effects of pore size, shape and content. The application of the Mie theory in absorbing media with one-size spherical pores is in progress. To determine the effect of the plasma-sprayed lamellar microstructure, a multilayer model should also be implemented. 


\section{References}

1. R. Siegel and C.M. Spuckler, Analysis of Thermal Radiation Effects on Temperature in Turbine Engine Thermal Barrier Coatings, Materials Science and Engineering, 1998, A245, p150-159.

2. L. Bianchi, A.C. Léger, M. Vardelle, A. Vardelle and P. Fauchais, Splat Formation and Cooling of Plasma-Sprayed Zirconia, Thin Solid Films, 1997, 305, p 35-47.

3. C. Moreau, P. Gougeon, M. Lamontagne, V. Lacasse, G. Vaudreuil and P. Cielo, On-Line Control of the Plasma Spraying Process by Monitoring the Temperature, Velocity and Trajectory of In-Flight Particles, Proceedings of the 7th National Thermal Spray Conference, C.C. Berndt and S. Sampath, Ed., June 20-24, 1994, Boston, p431-437.

4. V. Debout, A. Vardelle, E. Meillot, P. Abélard, E. Bruneton, P. Fauchais et al., Correlation between Processing Parameters, Microstructure and Optical Properties for Plasma-Sprayed Yttria-Stabilized Zirconia Coatings, 17th International Symposium on Plasma chemistry, J. Mostaghimi et al., Ed., Univ. of Toronto Press, Pub., August 7-12, 2005, Toronto, Canada.

5. J.I. Eldridge, C.M. Spuckler, K.W. Street and J.R. Markham, Infrared Radiative Properties of Yttria-Stabilized Zirconia Thermal Barrier Coatings, Ceramic Engineering Science Proceedings, 2002, 23(4), p 417-429.

6. M. Vardelle, A. Vardelle, A.C. Léger and P. Fauchais, Dynamics of Splat Formation and Solidification in Thermal Spraying Processes, Proceedings of the 7th National Thermal Spray Conference, C.C. Berndt and S. Sampath, Ed., ASM Int. Materials Park, OH, USA, Pub., June 20-24, 1994, Boston, p 555-562.

7. R. MacPherson, The Relationship between the Mechanism of Formation, Microstructure and Properties of Plasma-Sprayed Coatings, Thin Solid Films, 1981, 83, p173-181.

8. K. Shinoda, Y. Kojima and T. Yoshiba, In Situ Measurement System for Deformation and Solidification Phenomena of Yttria-Stabilized Zirconia Droplets Impinging on Quartz Glass Substrate under Plasma-Spraying Conditions, Journal of Thermal Spray Technology, 2005, 14(4), p 511-517.

9. B. Maheu, J.N. Toulouzian and G. Gouesbet, Four Flux Models to Solve the Scattering Transfer Equation in terms of Lorentz Mie Parameters, Applied Optics, 1984, 23(19), p 3353-3362.

10. M. F. Modest, Radiative Heat Transfer, Mc Graw-Hill Edition, New York, 1993. 